\title{
ESTUDO DA TROCA DE AGREGADOS CONVENCIONAIS POR VIDRO MOÍDO EM BLOCOS DE CONCRETO NÃO ESTRUTURAL
}

\author{
STUDY OF EXCHANGE OF CONVENTIONAL AGGREGATES FOR MILLED GLASS \\ IN NON-STRUCTURAL CONCRETE BLOCKS
}

\author{
Daniel Borges Couto ${ }^{1}$ \\ Daniel de Sousa Melo Júnior ${ }^{2}$ \\ Teófanes Antônio Stacciariani Duarte ${ }^{3}$
}

\begin{abstract}
RESUMO: O presente artigo apresenta um estudo de comparação na troca de agregado convencional por vidro moído nos blocos de concreto não estruturais, com finalidade de investigar os possíveis benefícios da substituição de algumas porcentagens de vidro moído por brita. O trabalho tem como objetivo a produção de blocos utilizando o vidro moído em sua composição, em três diferentes proporções, a saber: dez, vinte e trinta por cento em massa, com a intenção de comparar suas propriedades, como massa, resistência e custo de produção, com os blocos de concreto convencionais, além de submetê-los a ensaios para avaliar sua qualidade. A metodologia apresenta como se executou a produção dos blocos relatando os detalhes do traço e das etapas que seguiram até o fim de sua cura, assim como os sistemas utilizados para os ensaios. Após as avaliações dimensionais e de resistência à compressão, concluiu-se que a adição de vidro moído em quaisquer umas das três proporções mantiveram os blocos dentro dos parâmetros das normas brasileiras, mas a proporção de $20 \%$ (vinte por cento) foi a melhor dentre as testadas.
\end{abstract}

Palavras-chave: Blocos de concreto. Alvenaria de vedação. Vidro moído.

ABSTRACT: This article presents a comparison study on the exchange of conventional aggregate for ground glass in non-structural concrete blocks, in order to investigate the possible benefits of replacing some percentages of ground glass with crushed glass. The work aims to produce blocks using ground glass in its composition, in three different proportions, namely: ten, twenty and thirty percent by mass, with the intention of comparing its properties, such as weight, strength and weight. production cost, with conventional concrete blocks, in addition to subjecting them to tests to assess their quality. The methodology shows how the blocks were produced, reporting the details of the line and the steps that followed until the end of its cure, as well as the systems used for the tests. After dimensional and compressive strength evaluations, it was concluded that the

\footnotetext{
Graduando em Engenharia Civil, Faculdade Aldete Maria Alves/FAMA, Iturama/MG. daniecoutodaniel@live.com

2 Graduando em Engenharia Civil, Faculdade Aldete Maria Alves/FAMA, Iturama/MG. danieldjjunior@hotmail.com

${ }^{3}$ Prof. Esp. Eng. Docente da Faculdade Aldete Maria Alves/FAMA, Iturama/MG. teofanes@bol.com.br
} 
addition of ground glass in any of the three proportions kept the blocks within the parameters of Brazilian standards, but the proportion of $20 \%$ (twenty percent) was the best among those tested.

Keywords: Concrete blocks. Sealing masonry. Ground glass.

\section{INTRODUÇÃO}

O presente trabalho consiste avaliar a substituição do agregado areia pelo agregado vidro moído na confecção de blocos de concreto. A ideia surgiu a partir da observação de que o vidro moído hoje é um subproduto da sociedade moderna é um produto de fácil reciclagem além de ser bastante abundante. Estima-se que cerca de $47 \%$ das embalagens de vidro foram recicladas em 2011 no Brasil, somando $470 \mathrm{mil} \mathrm{ton/ano} \mathrm{(CEMPRE,} \mathrm{20II).}$ Apesar de expor um dado desatualizado, ainda é um dado que mostra o potencial para reciclagem, pois mais da metade do que foi produzido naquele ano não foi reciclado.

O advento do Cimento Portland, possibilitou a industrialização do concreto, tornando possível a viabilização de vários tipos de edificações para diversas finalidades. Todos os materiais que constituem o concreto são naturais e não renováveis, ou seja, estão sujeitos a se extinguirem caso a exploração ocorra de forma desenfreada e não surjam novos compostos substitutos.

Os blocos de concreto já são utilizados há bastante tempo nas construções brasileiras, e são uma boa solução para fechamento de alvenaria. Entretanto, por serem fabricados com produtos com alto peso específico, acabam gerando cargas significativas nos locais onde são utilizados.

Para a eficiência estrutural, um tema recorrente é a aplicação de cargas permanentes inferiores às usuais no sistema estrutural a fim de conseguir uma economia financeira no dimensionamento e execução do mesmo. Uma das soluções para esse problema é o uso de blocos de concreto para a alvenaria de vedação.

Os blocos de concreto com a adição de vidro moído são elementos de concreto que usam em sua composição vidro moído como agregado miúdo, reduzindo assim seu peso específico, o que diminui as cargas permanentes provocadas pela alvenaria no sistema estrutural, tornando possível um dimensionamento mais eficaz e econômico tanto da superestrutura quanto da infraestrutura, assim como outro ponto a ser levado em 
consideração é a possibilidade de usar este bloco de concreto para construir em solos com menos capacidade de carga, diminuindo assim a pressão da alvenaria sobre as formas.

Todos esses fatores citados refletem diretamente na diminuição do custo final da construção e em sua qualidade.

Importante destacar também, que segundo a NBR 6136/2016:

Os agregados graúdos e miúdos devem estar de acordo com a ABNT NBR 72II. Escórias de alto forno, cinzas volantes, argila expandida ou outros agregados leves ou não, podem ser usados com a condição de que o produto final atenda aos requisitos físico-mecânicos prescritos em 5.3. A dimensão máxima característica do agregado não ultrapasse a metade da menor espessura de parede do bloco (ASSOCIAÇÃO BRASILEIRA DE NORMAS TÉCNICAS, p.4, 2оı6).

Assim, evidencia-se que, desde que se atenda às exigências físico-mecânicas da NBR 6136, qualquer produto pode ser utilizado como agregado graúdo e/ou miúdo na composição do concreto para fabricação de blocos, como o vidro moído, objeto da investigação deste trabalho.

Lima et al (2012), a respeito da substituição de areia por vidro moído, em seu artigo a respeito da análise de concretos produzidos com vidro moído quando submetidos à elevadas temperaturas, destaca que "o teor de substituição mais adequado nesta pesquisa foi de $20 \%$, pois atingiu-se um patamar de resistência equivalente ao concreto sem substituição".

Assim, são objetivos deste trabalho a produção de blocos de concreto com a troca de uma porcentagem de agregado miúdo por vidro moído, nas proporções de $10 \%$, 20\% e $30 \%$ em massa, analisando suas propriedades físicas e mecânicas através da realização de ensaios normatizados, e verificar se há consonância entre os resultados obtidos e pesquisas já apresentadas na bibliografia consultada.

\section{DESENVOLVIMENTO}

\section{I FUNDAMENTAÇÃO TEÓRICA}

De acordo com Rossignolo (2009, p.15)

O concreto de cimento Portland é o material de construção mais utilizado em todo mundo. Isso se deve, ao menos em parte, ao fato de seus componentes serem produzidos, de modo relativamente fácil, a partir do emprego de matérias-primas locais, bem como pelo fato de o concreto ter uma aplicação versátil, adaptando-se facilmente às condições existentes. 
Sendo o concreto o material mais utilizado na construção civil, é substancial o estudo de maneiras de aprimorar o material e as técnicas utilizadas para sua fabricação e uso, para que haja o aperfeiçoamento de suas características, a sustentabilidade ambiental e o diferencial no custo. Desta forma, Tinoco e Silva Júnior (2018) destacam que "paralelamente à demanda de consumo de setores industriais, existe o problema do grande número de objetos e materiais vítreos que têm destinação inadequada, não passando por reaproveitamento ou reciclagem e sendo descartados em lixões ou no meio ambiente". Assim, a utilização de vidro para substituir alguma parte da areia no concreto torna-se uma importante alternativa de reciclagem deste material.

\section{I.I CARACTERÍSTICAS DO CONCRETO CONVENCIONAL}

A finalidade na produção do concreto é produzir uma mistura homogênea de modo que ao fim do seu tempo de cura consiga adquirir as propriedades físicas e mecânicas de projeto. O produto pode ser fabricado tanto no local do uso, quanto em usinas concreteiras.

O concreto convencional é formado pela mistura em proporções pré-determinadas (traço do concreto) de cimento Portland que é um aglomerante hidráulico, agregado miúdo (areia), agregado graúdo (brita) e água. A fim de melhorar ou modificar certas propriedades, pode ser adicionado materiais chamados aditivos (ABCP, 2009).

O cimento Portland é um material de pequena granulometria, considerado pulverulento, sendo sua composição química composta de silicatos e aluminatos de cálcio, sendo estes responsáveis pelo endurecimento da massa após reagirem e hidratarem com a água, obtendo-se assim a resistência mecânica do produto final.

Segundo Petrucci (1998, p. 5)

O cimento Portland resulta da moagem de um produto denominado clínquer, obtido pelo cozimento até fusão incipiente $(+/-30 \%$ de fase líquida) de mistura de calcário e argila convenientemente dosada e homogeneizada, de tal forma que toda cal se combine com os compostos argilosos, sem que, depois do cozimento, resulte cal livre em quantidade prejudicial. Após a queima, é feita pequena adição de sulfato de cálcio, de modo a que o teor de $\mathrm{SO}_{3}$ não ultrapasse 3,o\%, a fim de regularizar o tempo de início das reações do aglomerante com a água.

A hidratação do cimento Portland se dá pela reação da água com os diversos compostos constituintes do cimento, e essas reações dão origem ao processo de endurecimento. Para Petrucci (1998, p. 12) “[...] a hidratação do cimento consiste na 
transformação de compostos anidros mais solúveis em compostos hidratados menos solúveis".

A mistura do cimento com a água forma uma pasta plástica, mas conforme a hidratação vai acontecendo, essa pasta começa a perder a plasticidade. O momento entre a adição da água até o momento em que a pasta começa a perder a plasticidade é chamado de tempo de início de pega, que tem como característica o aumento de temperatura e de viscosidade. Do mesmo modo, quando a pasta perde totalmente a plasticidade, tornando-se rígida, este momento é chamado de fim de pega, onde a pasta não pode mais ser deformada. A partir do fim da pega inicia-se a fase de endurecimento, onde o material começa a adquirir sua resistência.

Os agregados são materiais granulares sem volume e formas definidos. Além da resistência mecânica do cimento hidratado, os agregados também contribuem o ganho de resistência do concreto.

Dentre diversas classificações disponíveis, os agregados podem ser divididos em miúdos e graúdos, podendo ter diferentes origens (PETRUCCI, 1998, p. 48).

O concreto é um material utilizado para trabalhar à compressão, sendo baixíssima sua resistência à tração e ao cisalhamento. $O$ tempo padrão para o concreto adquirir praticamente toda a resistência para qual foi projetado (cura) são 28 dias (ASSOCIAÇÃO BRASILEIRA DE NORMAS TÉCNICAS, 2019).

\subsubsection{CONCRETO COM VIDRO MOÍDO PARA BLOCOS DE ALVENARIA SEM FUNÇÃO ESTRUTURAL}

A produção do bloco de concreto com vidro moído constitui na substituição total ou parcial do agregado miúdo (areia) do concreto convencional por um agregado miúdo de vidro moído, obtido da reciclagem desse material.

Quanto à qualidade do concreto e suas propriedades no estado fresco e endurecido, leva-se em consideração os mesmos fatores descritos para o concreto convencional.

Os materiais utilizados na fabricação do concreto com vidro moído são basicamente os mesmos utilizados na produção do concreto convencional, com as mesmas características, com exceção do agregado miúdo que no concreto com vidro moído é substituído pelo agregado vidro moído. 
A utilização de alvenarias de blocos de concreto com vidro moído em sua composição deve continuar atendendo às exigências da NBR 6120/2019 - Ações para o cálculo de estruturas de edificações (ASSOCIAÇÃO BRASILEIRA DE NORMAS TÉCNICAS, 2019), o que exige blocos com novos agregados com massa igual ou inferior aos blocos convencionais de iguais medidas. $O$ peso específico aparente do concreto convencional é $24 \mathrm{kN} / \mathrm{m}^{3}$, valor esse limite para o peso específico do concreto executado com vidro moído.

\subsubsection{PROPRIEDADES DOS BLOCOS DE CONCRETO EXIGIDAS PELA NORMA ABNT NBR 6r36/2016}

De acordo com a ABNT NBR 6136/2016 - Blocos vazados de concreto simples para alvenaria - requisitos (ASSOCIAÇÃO BRASILEIRA DE NORMAS TÉCNICAS, 2016), os blocos que atendem à condição de blocos com ou sem função estrutural, para uso em elementos de alvenaria acima do solo, pertencem à Classe C. São esses os blocos alvo deste trabalho.

Assim, tomando-se como referência a tabela extraída da norma ABNT NBR 6136/2016 (Tabela I), tem-se que a resistência característica à compressão axial (resistência característica fbk obtida aos 28 dias) nessa classe de blocos deverá ser igual ou superior a 3,o MPa (ASSOCIAÇÃO BRASILEIRA DE NORMAS TÉCNICAS, p.7, 2016).

Tabela I - Requisitos para resistência característica à compressão, absorção e retração

Fonte: ABNT NBR 6136/2016

\begin{tabular}{|c|c|c|c|c|c|c|c|}
\hline \multirow{3}{*}{ Classificação } & \multirow{3}{*}{ Classe } & \multirow{3}{*}{$\begin{array}{c}\text { Resistência } \\
\text { característica à } \\
\text { compressão axial a } \\
\mathrm{MPa}\end{array}$} & \multicolumn{4}{|c|}{$\begin{array}{c}\text { Absorção } \\
\%\end{array}$} & \multirow{3}{*}{ Retração d \% } \\
\hline & & & \multicolumn{2}{|c|}{ Agregado normal ${ }^{b}$} & \multicolumn{2}{|c|}{ Agregado leve ${ }^{C}$} & \\
\hline & & & Individual & Média & Individual & Média & \\
\hline \multirow{2}{*}{$\begin{array}{c}\text { Com função } \\
\text { estrutural }\end{array}$} & A & $f_{\mathrm{bk}} \geq 8,0$ & $\leq 9,0$ & $\leq 8,0$ & \multirow{3}{*}{$\leq 16,0$} & \multirow{3}{*}{$\leq 13,0$} & \multirow{3}{*}{$\leq 0,065$} \\
\hline & B & $4,0 \leq f_{b k}<8,0$ & $\leq 10,0$ & $\leq 9,0$ & & & \\
\hline $\begin{array}{l}\text { Com ou } \\
\text { sem função } \\
\text { estrutural }\end{array}$ & C & $f_{\mathrm{bk}} \geq 3,0$ & $\leq 11,0$ & $\leq 10,0$ & & & \\
\hline \multicolumn{8}{|c|}{$\begin{array}{ll}\text { a } & \text { Resistência característica à compressão axial obtida aos } 28 \text { dias. } \\
\text { b } & \text { Blocos fabricados com agregado normal (ver definição na ABNT NBR 9935). } \\
\text { c } & \text { Blocos fabricados com agregado leve (ver definição na ABNT NBR 9935). } \\
\text { d } & \text { Ensaio facultativo. }\end{array}$} \\
\hline
\end{tabular}


Com relação às dimensões dos blocos, a NBR 6136/2016 prevê que as dimensões nominais para os blocos desse estudo, família ıox40, são as seguintes: largura $90 \mathrm{~mm}$, altura $190 \mathrm{~mm}$ e comprimento $390 \mathrm{~mm}$, com tolerância de $+-2,0 \mathrm{~mm}$ para a largura e +- 3,0 mm para a altura e para o comprimento (ASSOCIAÇÃO BRASILEIRA DE NORMAS TÉCNICAS, 2016). Assim, em termos dimensionais os limites mínimos aceitos pela norma são: largura $88 \mathrm{~mm}$, altura $187 \mathrm{~mm}$ e comprimento $387 \mathrm{~mm}$, e os limites máximos aceitáveis são: largura $92 \mathrm{~mm}$, altura $193 \mathrm{~mm}$ e comprimento $393 \mathrm{~mm}$.

\section{METODOLOGIA}

Em conformidade com os objetivos propostos neste artigo, elaborou-se uma metodologia de forma a que os resultados obtidos fornecessem as informações necessárias para a análise crítica do tema. Após o levantamento bibliográfico, produziram-se os blocos de concreto em quantidade suficiente para os ensaios propostos e após a realização dos ensaios, foi feita a comparação com o bloco de concreto convencional.

A produção dos blocos foi realizada no dia 8 de fevereiro de 2020 em uma fábrica de blocos de concreto localizada no município de Campina Verde - MG.

Como a NBR 12118/2013 (ASSOCIAÇÃO BRASILEIRA DE NORMAS TÉCNICAS, 2013) exige que para os ensaios de compressão sejam rompidos seis blocos de cada lote, foram produzidos 4 lotes com 12 peças cada lote, distribuídos da seguinte forma: o primeiro lote, testemunha, foi fabricado de acordo com o padrão da fábrica, sem nenhuma modificação no traço do concreto normalmente utilizado. $O$ segundo lote recebeu $10 \%$ de vidro moído em volume em substituição ao agregado miúdo areia na composição do concreto. O terceiro lote recebeu 20\% e o último lote, 30\% de vidro moído.

Para a produção do lote testemunha, o traço utilizado foi o mesmo que a fábrica adota na sua produção normal de blocos classe C (ABNT 6136). É o traço recomendado pelo fabricante dos equipamentos de produção de blocos, e, em massa esse traço é de I:2,40:0,6o, para cimento, agregado miúdo areia e relação água/cimento.

A tabela 2 mostra as quantidades de materiais em massa, segundo o traço adotado e com as substituições parciais de areia por vidro moído, para fabricação dos lotes de I2 blocos. 
Tabela 2 - Traço utilizado na fabricação dos blocos com uso parcial de vidro moído como agregado miúdo

\begin{tabular}{|c|c|c|c|c|c|}
\hline$\%$ VIDRO & $\begin{array}{l}\text { CIMENTO } \\
(\mathrm{kg})\end{array}$ & AREIA (kg) & $\begin{array}{l}\text { VIDRO } \\
(\mathrm{kg})\end{array}$ & $\begin{array}{l}\text { ÁGUA } \\
(\mathrm{kg})\end{array}$ & $\begin{array}{l}\text { TOTAL } \\
(\mathrm{kg})\end{array}$ \\
\hline 0,0 & 30,0 & 72,0 & 0,0 & $\mathrm{I} 8, \mathrm{o}$ & 120,0 \\
\hline Io,o & 30,0 & 64,8 & 7,2 & $\mathrm{I} 8, \mathrm{o}$ & 120,0 \\
\hline 20,0 & 30,0 & 57,6 & 14,4 & $\mathrm{I} 8, \mathrm{o}$ & 120,0 \\
\hline 30,0 & 30,0 & 50,4 & 21,6 & $\mathrm{I} 8, \mathrm{o}$ & 120,0 \\
\hline
\end{tabular}

Fonte: Autores

Após a separação das quantidades de materiais conforme o traço, realizada com apoio de uma balança graduada em gramas (g) com precisão de I,o g (figura I), apresentando o resultado em gf (grama-força), foi feita a mistura em betoneira elétrica de capacidade 4001.

Figura I - pesagem de materiais

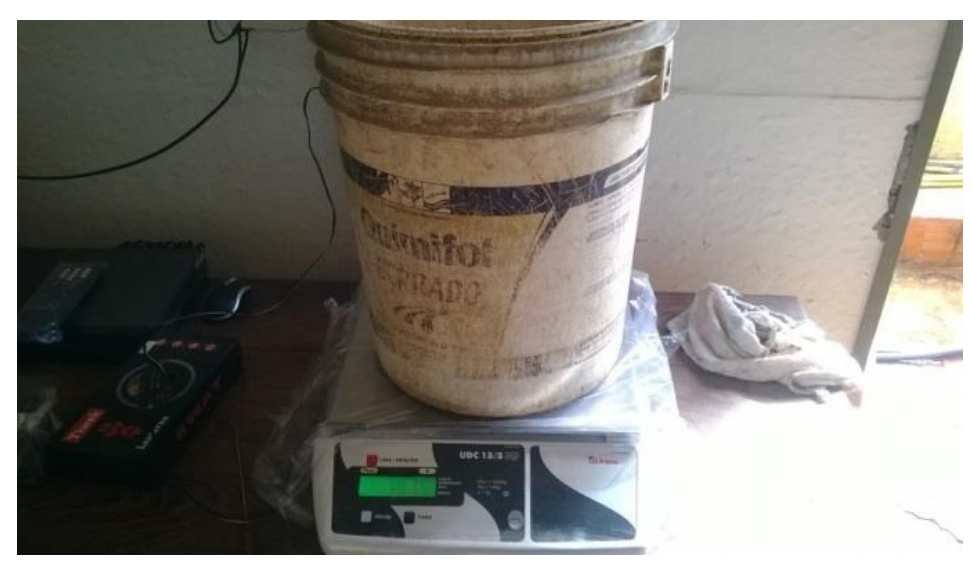

Fonte: Autores

Colocou-se vidro moído na betoneira e em movimento, adicionou-se o cimento. Em seguida foi colocada uma porção d'água, a areia e o restante da água. O tempo da mistura foi de aproximadamente cinco minutos para cada batida.

Após a argamassa ser misturada em betoneira, colocou-se a mistura na prensa manual vibratória para a confecção dos blocos (Figura 2). O efeito vibratório por motor elétrico tem função de adensar a massa, excluindo assim os espaços vazios do concreto deixando a peça sólida. 
Figura 2 - colocação da mistura na prensa vibratória

Fonte: Autores

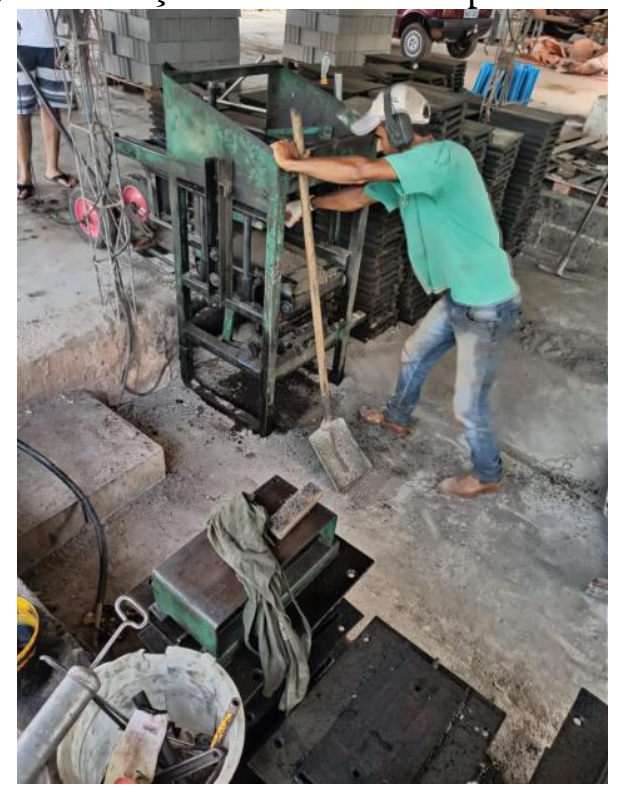

Após a prensagem, os blocos são recolhidos em pequenos paletes de madeira e são transportados para a área onde ocorrerá o processo de cura (Figura 3).

Figura 3 - início do processo de cura com aspersão de água

Fonte: Autores

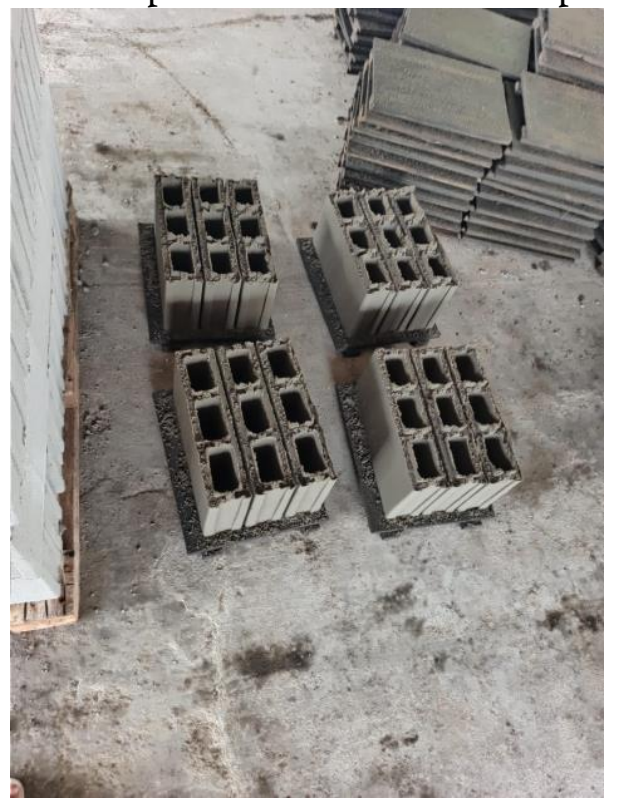

Após o tempo de cura mínimo de 28 dias, os ensaios foram realizados nos laboratórios da Faculdade FAMA de Iturama - MG no dia i6 de junho de 2020, acompanhados pelo prof. orientador. 
Com uma balança graduada em quilograma força (kgf), com precisão de I grama, pesaram-se seis blocos de concreto convencional de mesmas dimensões e idade dos blocos de concreto com vidro. Em seguida pesaram-se os três lotes de seis blocos de concreto com vidro (Figura 4). Para comparação dos pesos, foi adotado o valor médio entre os valores de cada tipo de bloco.

Figura 4 - pesagem dos blocos de concreto convencional e leve

Fonte: Autores

As três principais dimensões (altura x largura $\mathrm{x}$ comprimento) dos blocos foram aferidas com o paquímetro ilustrado na figura 5.

Figura 5 - paquímetro do laboratório da faculdade FAMA

Fonte: Autores

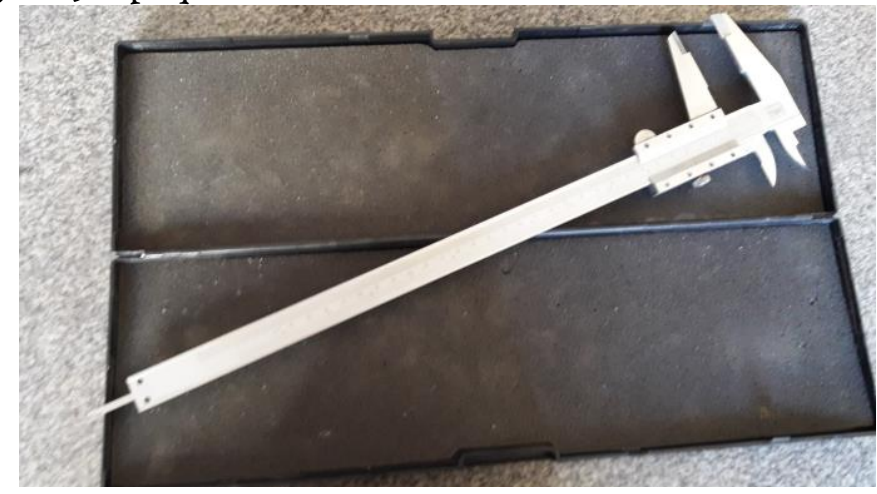

Seguindo as orientações da ABNT NBR 12118:2013 - blocos vazados de concreto simples para alvenaria - métodos de ensaio, realizaram-se os ensaios de resistência à compressão. 
O ensaio de resistência à compressão consiste no rompimento dos corpos de prova (os próprios blocos de concreto) com prensa hidráulica manual equipada com placas de aço para cobrir a superfície do bloco proporcionando uma distribuição da carga aplicada através da superfície. Para cada lote de 12 blocos fabricados com as porcentagens de vidro na composição da massa, foram ensaiados seis blocos, conforme orientação da ABNT NBR 6136/2016.

Os ensaios foram realizados utilizando-se a prensa hidráulica com célula de carga graduada em tonelada-força ( $\mathrm{Tf}$ ), dos laboratórios da Faculdade FAMA, conforme exibido na Figura 6.

Fonte: Autores

Figura 6 - rompimento dos blocos por prensa hidráulica

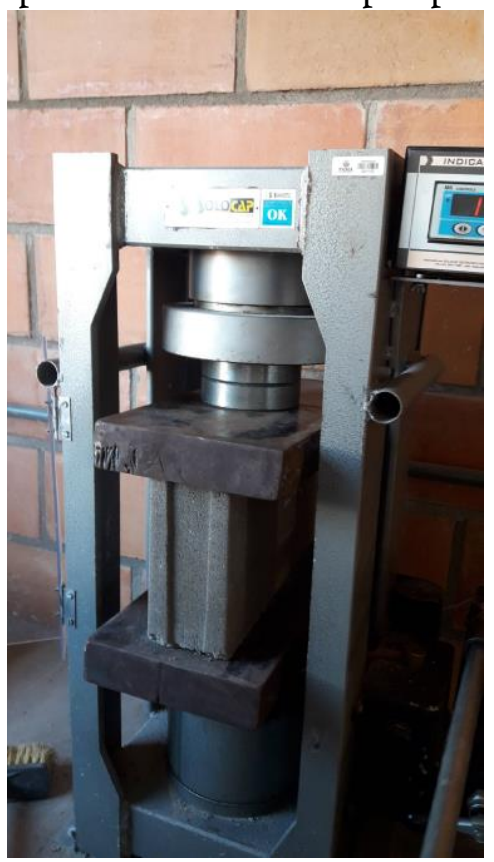

Importante observar no detalhe da figura 6 a montagem do sistema de rompimento do corpo de prova à compressão, com o uso das placas metálicas para distribuição dos esforços.

\section{RESULTADOS E DISCUSSÃO}

As medições executadas nos corpos de provas, segundo as recomendações da norma NBR 6136/2016, foram compiladas na tabela 3. Para cada lote com uma porcentagem específica de vidro na composição, foram utilizados seis corpos de prova, totalizando vinte 
e quatro ensaios. Assim a tabela 3 reflete um universo com todas as informações coletadas no laboratório, para cada bloco.

Tabela 3 - Características dos blocos de concreto

\begin{tabular}{|c|c|c|c|c|c|c|c|c|}
\hline $\mathrm{CP}$ & 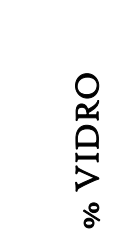 & 怘 & 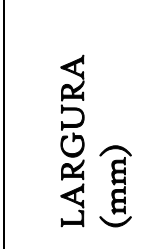 & 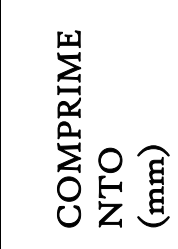 & $\begin{array}{l}30 \\
4 \\
\infty \\
\infty \\
\infty\end{array}$ & 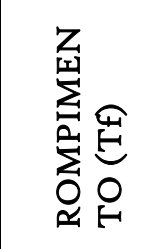 & 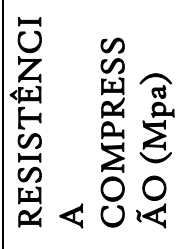 & 岂 \\
\hline I & o & 191,5 & 92,9 & 389,0 & 8525,0 & 14,34 & 3,89 & I231,86 \\
\hline 2 & o & 190,0 & 94,0 & 391,0 & 8436,0 & II, 33 & 3,02 & 1208,03 \\
\hline 3 & o & 190,8 & 93,3 & 389,0 & 8694,0 & 13,86 & 3,75 & I255,48 \\
\hline 4 & o & 191,5 & 94,0 & 390,0 & 8658,0 & II,76 & 3,15 & 1233,26 \\
\hline 5 & o & 191,4 & 93,9 & 391,0 & 8665,0 & \begin{tabular}{|l}
16,92 \\
\end{tabular} & 4,52 & \begin{tabular}{|l|}
1233,06 \\
\end{tabular} \\
\hline 6 & o & 191,0 & 91,7 & 389,0 & 8691,0 & 14,90 & 4,10 & I275,61 \\
\hline 7 & Io & 191,5 & 94,3 & 390,0 & 8205,0 & II, 73 & 3,13 & 1165,02 \\
\hline 8 & Io & 190,5 & 93,8 & 389,0 & 8090,0 & 8,33 & 2,24 & II63,86 \\
\hline 9 & Io & 190,5 & $94, \mathrm{I}$ & 391,0 & 7870,0 & II, 83 & 3,15 & 1122,83 \\
\hline Io & IO & 190,0 & 92,0 & 390,0 & 8125,0 & 15,43 & 4,22 & II 191,84 \\
\hline II & Io & 191,5 & 94,0 & 390,0 & 8205,0 & 13,50 & $3,6 \mathrm{I}$ & II 68,74 \\
\hline 12 & Io & 190,5 & 92,9 & 391,o & 8040,0 & \begin{tabular}{|l}
18,22 \\
\end{tabular} & 4,92 & II6I,90 \\
\hline 13 & 20 & I9I,I & $92, \mathrm{I}$ & 390,0 & 7870,0 & 13,47 & 3,68 & II 46,54 \\
\hline 14 & 20 & I9o,8 & 93,3 & 389,0 & 7925,0 & I4,6I & 3,95 & II 44,43 \\
\hline 15 & 20 & I9I, 4 & 93,9 & 390,0 & 8040,0 & 15,66 & 4,19 & 1147,05 \\
\hline 16 & 20 & 190,5 & 93,8 & 389,0 & 7895,0 & 11,55 & $3, \mathrm{II}$ & $\mathrm{II} 35,8 \mathrm{I}$ \\
\hline 17 & 20 & 191,6 & 94,2 & 390,0 & 7980,0 & 14,85 & 3,97 & 1133,68 \\
\hline I8 & 20 & 190,7 & 91,9 & 391,0 & 7750,0 & 18,22 & 4,97 & I1130,99 \\
\hline 19 & 30 & I91,6 & 94,4 & 389,0 & 8ого,o & $\mathrm{II}, 2 \mathrm{I}$ & 2,99 & 1138,45 \\
\hline 20 & 30 & I9I,I & $94, \mathrm{I}$ & 390,0 & 7920,0 & 7,95 & 2,13 & 1129,30 \\
\hline 21 & 30 & 191,0 & 93,6 & 390,0 & 7865,0 & 8,05 & 2,16 & $\mathrm{II} 28, \mathrm{O} 4$ \\
\hline 22 & 30 & 191,o & 92,0 & 390,0 & 7805,0 & 9,97 & 2,73 & 1138,90 \\
\hline 23 & 30 & 191,5 & 91,7 & 390,0 & 7915,0 & I6,98 & 4,66 & III5 \\
\hline 24 & 30 & I9I,o & 94,0 & 389,0 & 7865,0 & 9,57 & 2,57 & 1126,13 \\
\hline
\end{tabular}

A partir dos dados coletados, passa-se ao tratamento estatístico das amostras para se buscar alguma conclusão a respeito da pesquisa.

O primeiro passo é agrupar as informações, calculando-se os valores médios dos lotes, separando-os apenas pela porcentagem de vidro adicionada, visto que esta é a variável cuja ação deve ser investigada. A tabela 4 apresenta esses cálculos. 
Tabela 4 - Valores médios das características físicas dos blocos ensaiados por \% vidro adicionado.

\begin{tabular}{l|l|l|l|l|l|l|l}
\hline & & & & & \\
\end{tabular}

Fonte: Autores

Com os dados da tabela 4, pode-se observar que os valores médios das dimensões principais dos blocos (altura x largura x comprimento) estão muito próximos uns dos outros, mostrando grande homogeneidade na execução. O coeficiente de variação, abordado a seguir, trará uma noção quantitativa mais exata.

Outra observação imediata, relacionada com os valores médios, é que com o aumento da \% de vidro na composição, a massa dos blocos diminui o que reflete também na diminuição do peso específico dos blocos com maior porcentagem de vidro.

Essa é uma importante constatação, pois destaca uma consequência muito positiva da adição de vidro aos blocos, que é a diminuição de seu peso.

As forças de ruptura apresentadas são resultado da leitura direta da célula de carga. São valores importantes, mas a norma recomenda trabalhar com o parâmetro Resistência Característica à Compressão Axial, o que é conseguido através do quociente entre a carga de ruptura pela área de aplicação da carga, em unidades do Sistema Internacional.

Como já visto anteriormente, para os blocos classe C, a NBR 6136/2016 estabelece que a Resistência Característica à Compressão Axial seja igual ou maior que 3,o MPa. Assim, considerando-se os valores médios obtidos, imediatamente já se conclui que adição de $30 \%$ de vidro é inviável, pois com 2,87 Mpa, não atende a norma no quesito resistência. Já as formulações com I0\% e 20\%, com valores de resistência de 3,55 Mpa e 3,98 Mpa, respectivamente, atendem à referida norma. 
Outrossim, comparando os valores de resistência dos blocos com vidro com os valores dos blocos testemunhas (sem adição de vidro), observa-se que a adição de $10 \%$ traz leve piora, caindo de 3,74 MPa do bloco testemunha, para 3,55 Mpa do bloco com vidro a $10 \%$.

A melhor situação foi verificada com a adição de $20 \%$ de vidro. Esse valor adicionado à formulação do traço dos blocos, elevou a resistência de 3,74 $\mathrm{MPa}$ do bloco testemunha para 3,98 MPa do bloco com 20\%.

Outra análise a ser feita é a da qualidade dos lotes amostrados. Para isso, uma forma de se comparar os parâmetros de forma quantitativa, é comparando-se o coeficiente de variação de cada parâmetro.

O coeficiente de variação é definido como o quociente entre o desvio padrão e a média, apresentados em porcentagem. Quanto menor o seu valor, mais homogêneos são os dados. Não há um parâmetro individual preestabelecido. O que conta é a comparação entre os lotes.

A tabela 5 mostra os cálculos dos coeficientes de variação dos dados medidos, para cada evento avaliado.

Tabela 5 - Coeficiente de variação

\begin{tabular}{|c|c|c|c|c|c|c|c|}
\hline 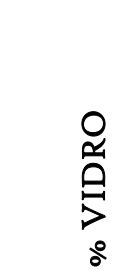 & 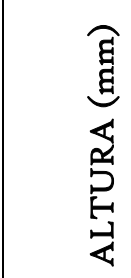 & 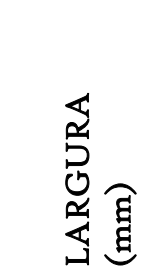 & 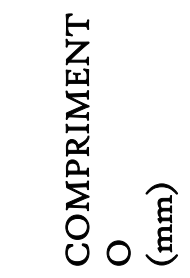 & 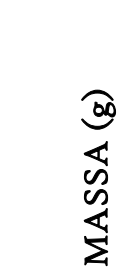 & 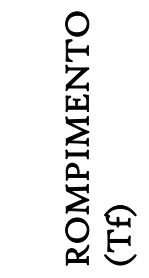 & 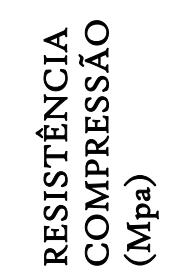 & 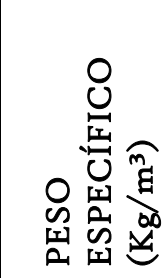 \\
\hline o & $0,30 \%$ & $0,97 \%$ & $0,25 \%$ & $\mathrm{I}, 23 \%$ & $14,97 \%$ & $15,25 \%$ & $\mathrm{I}, 87 \%$ \\
\hline Io & $0,32 \%$ & $0,95 \%$ & $0,19 \%$ & $1,55 \%$ & $25,86 \%$ & $26,40 \%$ & $\mathrm{I}, 92 \%$ \\
\hline 20 & $0,22 \%$ & $\mathrm{I}, 05 \%$ & $0,19 \%$ & $\mathrm{I}, 26 \%$ & $15,11 \%$ & $15,46 \%$ & $0,62 \%$ \\
\hline 30 & $0,14 \%$ & $\mathrm{I}, 24 \%$ & $0,13 \%$ & о,88\% & $31,52 \%$ & $32,58 \%$ & $0,97 \%$ \\
\hline
\end{tabular}

Fonte: Autores

Observa-se que em comparação ao lote testemunha, os valores dos parâmetros dimensionais são bem homogêneos e quando apresentam alguma variação, tendem a ser melhor do que a testemunha. Nos quesitos massa e peso específico também não há 
diferenças representativas. As maiores distorções apareceram nos valores de resistência à compressão.

\section{CONCLUSÃO}

O artigo de Lima et al (2012) "Análise de concretos produzidos com vidro moído quando submetidos a elevadas temperaturas", apresentado na XXXV Jornadas Sul Americanas de Engenharia Estrutural, destaca que a adição de $20 \%$ de vidro na composição de concretos é a melhor proporção, quando comparadas com outras que variavam de 5\% a $100 \%$.

Esta pesquisa também chegou a mesma conclusão: a substituição de parte do agregado miúdo areia por vidro moído na composição do concreto para fabricação de blocos mostrou que a proporção de $20 \%$ de vidro na massa trouxe melhorias com a diminuição da massa e do peso específico dos blocos, além de aumentar sua resistência à compressão em comparação com os blocos normalmente fabricados sem a adição de vidro.

Proporções menores, como o acréscimo de 10\%, trouxeram diminuição da massa e do peso específico dos blocos, mas não trouxeram ganho na resistência, embora os resultados obtidos nos ensaios ainda aprovem o uso desses blocos segundo as normas da Associação Brasileira de Normas Técnicas (ABNT).

O caso mais crítico, a adição de 30\%, foi a que resultou maior diminuição da massa e do peso específico dos blocos, mas, em compensação, foi o que teve maior perda na resistência à compressão, com valores abaixo do mínimo recomendado pela norma, reprovando o uso dessa proporção.

Assim, conclui-se que a substituição de areia por vidro moído na fabricação de blocos de concreto é uma alternativa promissora, permitindo reaproveitamento de resíduos de vidro. Também é importante que a sua adição à massa deva ser muito bem controlada, pois foi possível observar que há proporções que melhoram as características do concreto, como também há proporções que o inviabilizam. 


\section{REFERÊNCIAS}

ASSOCIAÇÃO BRASILEIRA DE CIMENTO PORTLAND - ABCP. Uma breve história do cimento Portland. Disponível em http://www.abcp.org.br/conteudo/basicosobre-cimento/historia/uma-breve-historia-do-cimento-portland\#.VHfcTTHF_qc, 2009. Acesso em: 19 abr. 2020.

ASSOCIAÇÃO BRASILEIRA DE NORMAS TÉCNICAS. NBR: 6120: Ações para o cálculo de estruturas de edificações. Rio de Janeiro. 2019.

NBR: 6136: Blocos vazados de concreto simples para alvenaria - Requisitos. Rio de Janeiro. 2016.

NBR: 72Ir: Agregados para concreto - Especificação. Rio de Janeiro. 2009. Versão Corrigida: 2019 .

NBR: 7215: Cimento Portland - Determinação da resistência à compressão de corpos de prova cilíndricos. Rio de Janeiro. 2019.

NBR: 12118: Blocos vazados de concreto simples para alvenaria - Métodos de ensaio. Rio de Janeiro. 2013.

CEMPRE, Compromisso Empresarial para Reciclagem. Vidro. São Paulo. 20ır. Disponível em http://cempre.org.br/artigo-publicacao/ficha-tecnica/id/6/vidro, 2020.

LIMA, Rogério. RIGHI, Débora. KÖHLER, Lucas. TABARELLI, Aline. KIRCHHOF, Larissa. Análise de concretos produzidos com vidro moído quando submetidos a elevadas temperaturas. Artigo apresentado na XXXV Jornadas Sul Americanas de Engenharia Estrutural. Rio de Janeiro: 2012. Disponível em https://cimentoitambe.com.br/_downloads/artigo_vidro_moido.pdf. Acesso em: i9 abr. 2020 .

PETRUCCI, Eladio G. R. Concreto de cimento Portland. 13. ed. rev. e atual. São Paulo: Globo, 1998 .

ROSSIGNOLO, João Adriano. Concreto leve estrutural. São Paulo: Pini, 2009.

TINOCO, Vinícius Navarro Varela. SILVA JÚNIOR, Francisco Alves da. Revisão literária do uso de vidro moído como substituto do agregado miúdo no concreto. Universidade Federal Rural Do Semiárido - UFERSA. Curso de Bacharelado em Ciência e Tecnologia

Trabalho de Conclusão de Curso (2018). Disponível em: https://repositorio.ufersa.edu.br/bitstream/prefix/4271/2/ViniciusNVT_ART.pdf., 2018. Acesso em: 19 abr. 2020. 